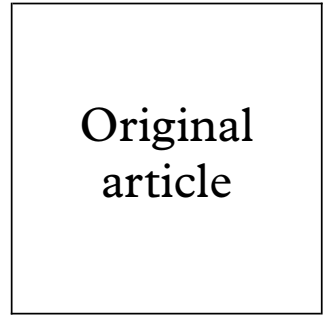

\author{
J Vioque, I Hernández-Aguado, E Fernandez García, M García de la Hera, \\ C Alvarez-Dardet
}

\title{
Prospective cohort study of female sex workers and the risk of HIV infection in Alicante, Spain (1986-96)
}

Objective: To measure the incidence of HIV infection over a 10 year follow up in a cohort of
female commercial sex workers in Alicante (Spain), and to determine factors associated with high risk of infection.

Methods: A prospective cohort study was carried in an AIDS information and prevention centre in Alicante, Spain. Of the 1388 female sex workers who initially sought the services of the centre since September 1986, 657 completed at least one additional follow up visit before December 1996. Main outcome measures were infection with HIV-1 and reported risk behaviours.

Results: During 1815 person years of observation among 657 female sex workers who were free of HIV infection (negative test), 16 women developed the HIV infection (incidence rate of HIV infection $=8.8$ cases $/ 1000$ woman years, $95 \%$ confidence interval $(\mathrm{CI}): 5.4-14.4)$. Reported current use of injecting drugs at the first visit was associated with an increased risk of HIV infection (relative risk, $\mathrm{RR}=12.87,95 \% \mathrm{CI}: 4.81-34.15$ ) as well as having an usual partner with injecting drug addiction ( $R R=20.89,95 \% \mathrm{CI}: 7.44-58.70)$. Infection also was associated with younger age ( $R R$ for 1 year $=0.86,95 \% \mathrm{CI}$ : 0.76-0.96). After multivariate adjustment using Poisson regression analysis, the factors that remained significantly associated with the risk of HIV infection were current use of injecting drugs $(\mathrm{RR}=4.61,95 \% \mathrm{CI}: 1.37-15.46)$, and having a usual partner with injecting drug addiction ( $R R=10.08,95 \% \mathrm{CI}: 2.94-34.57)$. There was also some evidence that a younger age could be related to infection.

Conclusion: These data suggest that the risk of HIV infection among this cohort of female sex workers in Alicante is predominately associated with the use of injecting drugs, and having a regular partner with injecting drug addiction. An increasing number of clients did not play a role in the risk of infection.

(Sex Transm Inf 1998;74:284-288)

Keywords: HIV; prostitutes; risk factors; injecting drug users

\section{Introduction}

The importance of heterosexual transmission of HIV infection in the developing world has been highlighted in several studies carried out in African and Asian countries where female sex workers are not only at very high risk of HIV infection but also important disseminators of the infection. ${ }^{1-5}$ In contrast, the role of sexual transmission of HIV infection in female sex workers in the developed world has not been fully clarified. Prevalence studies in female sex workers in North America and Europe have shown that the infection was much higher in injecting drug using (IDU) prostitutes than in non-IDU prostitutes, thus probably suggesting a transmission through IDU. ${ }^{6-8}$ In a prevalence study in Spain, a low prevalence of HIV infection was observed among non-IDU female sex workers, and an increased risk associated with a higher rate of sexual exposure and some unprotected sexual practices. $^{9}$

In spite of their relevance, prevalence studies may present serious problems in assessing the role of risk factors associated with the transmission of HIV infection because of their well known weakness in establishing a cause and effect relation. In this sense, prospective cohort studies may solve some of the inherent problems of prevalence studies as potential risk factors can be measured before the outcome. In addition, a prospective cohort study may be useful in monitoring the course of an epidemic among special populations as well as changes in the potential risk factors, thus allowing the evaluation of preventive interventions.

The aim of this study was to estimate the incidence of HIV infection in a cohort of female sex workers at Alicante (Spain) during 10 years of follow up, and to explore risk factors associated with the occurrence of HIV infection.

\section{Methods}

POPULATION

Overall, 1388 female sex workers have sought the services of the centre for information and prevention of AIDS in Alicante (Centro para la Información y Prevención del SIDA) since it opened in 1986. From this population, a total of 657 female sex workers who initially attended the centre and were free of HIV infection, have returned between September 1986 and December 1996. In addition to HIV testing the AIDS centre also provided STD testing and care, free condoms, and counselling to all attending women on a free basis. 
Table 1 Sociodemographic variables among 657 female sex workers. Alicante, Spain 1986-96

\begin{tabular}{|c|c|c|c|}
\hline Variables & $\begin{array}{l}\text { HIV seroconverter } \\
(n=16)\end{array}$ & $\begin{array}{l}\text { Persistent HIV }{ }^{*} \\
(n=641)\end{array}$ & $p$ Valuet \\
\hline \multicolumn{4}{|l|}{ Age } \\
\hline mean (SD) & $24.5(3.3)$ & $28.9(6.8)$ & \multirow[t]{2}{*}{0.003} \\
\hline median $(\mathrm{IQ}) \rrbracket$ & $24(23.5-26)$ & $27(25-33)$ & \\
\hline \multicolumn{4}{|c|}{ School leaving age (years) } \\
\hline mean $(\mathrm{SD})$ & $13.1(5.3)$ & $14.8(4.9)$ & \multirow[t]{2}{*}{$0.15 \ddagger$} \\
\hline median (IQ) $\mathbb{S}$ & $15(12.5-16)$ & $15(14-17)$ & \\
\hline \multicolumn{4}{|c|}{ Months in prostitution } \\
\hline mean (SD) & $36.4(53.8)$ & $40.1(54.8)$ & \multirow{2}{*}{$0.80 \ddagger$} \\
\hline median (IQ) & $12(6-36)$ & $18(4-60)$ & \\
\hline \multicolumn{4}{|c|}{ No of clients/week (first interview) } \\
\hline mean $(\mathrm{SD})$ & $27.8(14.2)$ & $23.3(17.2)$ & \multirow[t]{2}{*}{$0.29 \ddagger$} \\
\hline median (IQ)』 & $24(18-32.5)$ & $18(12-30)$ & \\
\hline
\end{tabular}

^HIV seroconverter to the human inmunodeficiency virus; HIV- = negative to HIV infection. $t \mathrm{t}$ Values derived from test for comparisons of means.

$\ddagger$ Comparisons were based in lower number because of some missing values.

§IQ = interquartile range (not available for HIV seroconverter owing to small numbers).

In this study, a female sex worker was defined as a woman who self reported as providing regular sexual services for money at the first visit and during the study period. Participation in the study was voluntary, and informed consent was always obtained.

DATA COLLECTION

At the time of the first visit, a structured questionnaire asking for information on sociodemographic characteristics, prostitution history, drug use behaviour, and private sexual partners was administered face to face by trained female interviewers in private rooms at the centre. Thus, the information on the exposure variables refers to the study entry, although for some women information was completed, verified, and corrected during following visits. The following variables were considered in the analyses: age, educational level; number of clients per week, sexual practices, current condom use during vaginal sexual contacts with commercial partners (never, rarely (0-33\%), irregularly (34-66\%), regularly $(>66 \%))$, duration of prostitution, working conditions, and the sectors of prostitution they worked in; injecting drug use, and its duration; previous transfusions; and for sexual private partners, their sexual practices, drug use, and HIV seropositivity status.

At the end of the first interview, participants were offered the HIV test on a 6 month schedule, and screening for sexually transmitted disease on a 3 month schedule. Thus, results of the HIV testing were only available after the interview was completed, thereby blinding the interviewer and the participant to the outcome and exposure measures.

Confidentiality was obtained by using individual numbers. Thus, only principal investigators were aware of the correspondence among personal interviews, blood testing results, and clinical records.

\section{LABORATORY METHODS}

HIV test were performed on serum samples at the local HIV reference laboratory using enzyme linked immunosorbent assay (ELISA), and western blot techniques to confirm positive results.
STATISTICAL ANALYSIS

Categorical variables were compared using the $\chi^{2}$ test; continuous variables were analysed using Student's $t$ test for means or nonparametric test (Mann-Whitney U test), if they were not normally distributed.

Incidence rates were calculated by dividing the number of events (HIV seroconversion) by the number of person years of follow up. Follow up time for each woman was taken at the time from her first negative HIV test to the time of her most recent negative HIV test or, if she seroconverted, the time of her first seropositive test. In order to explore the effect of variables measured on the risk of HIV infection, relative risks were calculated by dividing the incidence rate in an exposure category by the corresponding rate in the reference category. Relative risk and their corresponding $95 \%$ confidence intervals $(\mathrm{CI})$ were estimated using Poisson regression techniques ${ }^{10}$ available in the EGRET statistical package. ${ }^{11}$ Assessment of significance of variables was made by examining changes in the scaled deviance after adding each variable to a previous model. Factors that were associated with HIV infection in univariate analysis at the conventional level of significance $(p<0.05)$ were included in multivariate models in a forward stepwise process, exploring for confounding effects and interaction terms.

\section{Results}

A total of 657 female sex workers were included in our 10 year study period (1815 person years). During this time, 16 incident cases of HIV infection were diagnosed among the 657 female sex workers who were free of $\mathrm{HIV}$ infection at the first interview (negative test). The median number of HIV tests was three (range 2-30 HIV tests), very similar to the number of visits, as the test was offered on a free basis. The median duration of follow up was 1.9 years per woman, and the mean duration was 2.8 years per woman. The members of this cohort were aged 15-64 (median 27; interquartile (IQ) range, 25-33 years), and they had been working as female sex workers for between 1 month and 35 years (median 18 months; IQ range, 4 months to 5 years). Educational level was available for 636 of the women, $36(5.7 \%)$ had not received any formal education, and the median age at leaving school was 15 years (IQ range, 13-17 years). Most women were single (348 (53.0\%)) and 434 had one or more children. The distribution of women by the workplace where they practised prostitution was: $373(56.8 \%)$ in clubs, $218(33.2 \%)$ in flats or private referral (advertisement), $17(2.6 \%)$ at bars, and 33 $(5.0 \%)$ on the streets.

The country of birth was only available for 463 women as this information has only been collected since $1992 ; 301(65.0 \%)$ women were born in Spain, $100(21.6 \%)$ in South or Central America, 34 (7.3\%) in Africa, and 28 $(6.0 \%)$ in other European countries.

Women were asked about their clients and their use of condoms. The median number of clients in a typical working week was 18 (range 
Table 2 Univariate analysis (Poisson regression) for HIV seroconversion among 657 female sex workers. Alicante, Spain 1986-96

\begin{tabular}{|c|c|c|c|c|c|}
\hline \multicolumn{2}{|c|}{ Variables } & \multirow{2}{*}{$\begin{array}{l}\text { HIV } \\
\text { seroconverter }\end{array}$} & \multirow{2}{*}{$\begin{array}{l}\text { No } \\
657\end{array}$} & \multirow{2}{*}{$\frac{R R}{0.86}$} & \multirow{2}{*}{$\frac{95 \% C I^{\star}}{0.77-0.96}$} \\
\hline 1 & Age (years) & & & & \\
\hline 2 & $\begin{array}{l}\text { Duration of prostitution (months) } \\
\text { Missing values }(\mathrm{n}=22) \dagger\end{array}$ & 16 & 635 & 1.00 & $0.99-1.01$ \\
\hline \multirow[t]{5}{*}{3} & Workplace & & & & \\
\hline & Clubs & 11 & 362 & 1 & \\
\hline & Private & 1 & 267 & 0.21 & $0.03-1.66$ \\
\hline & Flats/private referral & 1 & 16 & 1.89 & $0.24-14.68$ \\
\hline & $\begin{array}{l}\text { Streets } \\
\text { Missing values }(n=16)+\end{array}$ & 3 & 30 & 4.30 & $1.20-15.41$ \\
\hline \multirow[t]{3}{*}{4} & Number of clients per week & & & & \\
\hline & $\begin{array}{l}\text { (1) First visit } \\
\text { Missing values }(n=2) \dagger\end{array}$ & 16 & 655 & 1.01 & $0.99-1.03$ \\
\hline & $\begin{array}{l}\text { (2) Last visit } \\
\text { Missing values }(\mathrm{n}=20) \dagger\end{array}$ & 16 & 637 & 1.02 & $1.00-1.04$ \\
\hline \multirow[t]{3}{*}{5} & IDU & & & & \\
\hline & No & 8 & 605 & 1.00 & \\
\hline & $\begin{array}{l}\text { Yes } \\
\text { Missing values }(n=2)\end{array}$ & 8 & 50 & 12.82 & $4.81-34.15$ \\
\hline \multirow[t]{4}{*}{6} & Regular partner IDU & & & & \\
\hline & No & 6 & 586 & 1.00 & \\
\hline & Yes & 9 & 42 & 20.89 & $7.44-58.70$ \\
\hline & Missing values $(n=29) \dagger$ & 1 & 29 & & \\
\hline \multirow[t]{3}{*}{7} & Regular partner HIV+ & & & & \\
\hline & No & 14 & 644 & 1.00 & \\
\hline & Yes & 2 & 13 & 6.04 & $1.37-26.58$ \\
\hline \multirow[t]{4}{*}{8} & Transfusion & & & & \\
\hline & No & 13 & 538 & 1.00 & \\
\hline & Yes & 2 & 61 & 1.44 & $0.32-6.38$ \\
\hline & Missing values $(n=58)$ & 1 & 58 & 0.93 & $0.12-7.41$ \\
\hline
\end{tabular}

$\star 95 \% \mathrm{CI}=95 \%$ confidence interval for relative risk.

tMissing values were not included in the analysis.

$\mathrm{IDU}=$ injecting drug use; $\mathrm{RR}=$ relative risk (rate ratio); HIV + = positive testing for human inmunodeficiency virus (HIV).

1-124; IQ range 12-28). Thirty four out of 641 women $(6.7 \%)$ who provided information said that they never used condoms with their clients when having vaginal intercourse, 171 used them rarely or irregularly, and 438 women $(68 \%)$ reported the use of condoms regularly.

In order to further characterise the women included in this cohort study, comparisons were made with the remaining 616 female sex workers who only attended the AIDS centre the first time. One hundred and fifteen women who tested HIV positive at the first visit were excluded from this comparison. The nonparticipant prostitutes in the cohort were slightly younger (median 26 years), they reported a higher proportion of current condom use with their clients $(p<0.001)$, and they presented a similar proportion of injecting drug use than female sex workers included in the cohort, $8.3 \%$ versus $7.6 \%$. No statistically significant differences were observed for other variables.

The average incidence during the study period was 8.8 cases per 1000 person years

Table 3 Multivariate Poisson regression analysis ${ }^{\star}$ for HIV seroconversion among female sex workers (analysis based in 627 observations; 30 missing values). Alicante, Spain 1986-96

\begin{tabular}{|c|c|c|c|c|c|}
\hline & & \multicolumn{2}{|l|}{ Cases } & \multirow[b]{2}{*}{$R R$} & \multirow[b]{2}{*}{$95 \% C I$} \\
\hline \multicolumn{2}{|c|}{ Variables } & $H I V+$ & $H I V-$ & & \\
\hline \multirow[t]{3}{*}{1} & IDU & & & & \\
\hline & No & 7 & 579 & 1.00 & \\
\hline & Yes & 8 & 48 & 4.61 & $1.37-15.46$ \\
\hline \multirow[t]{3}{*}{2} & Regular partner IDU & & & & \\
\hline & No & 6 & 585 & 1.00 & \\
\hline & Yes & 9 & 42 & 10.08 & $2.94-34.57$ \\
\hline
\end{tabular}

$\mathrm{HIV}=$ human inmunodeficiency virus; $\mathrm{CI}=$ confidence interval IDU = injecting drug use $\mathrm{RR}=$ relative risk (rate ratio)

*The model included indicator variables for IDU (no/yes) and regular partner IDU (no/yes). Missing values were not included in the analysis.
(95\%CI: 5.4-14.4 person years). Table 1 shows the age distribution, the age the women left school, the duration of prostitution, and the number of clients per week for the 657 women enrolled in the study by seroconverter status. The 16 incident cases were younger $(p=0.003)$ and left school at a younger age $(p=0.15)$; they also reported a shorter duration of prostitution and a higher number of clients per week but differences were not statistically significant.

To determine whether sociodemographic characteristics, and variables of prostitution history, private sexual partners, and drug use behaviour were associated with the risk of HIV infection, relative risks were estimated. Unfortunately, distribution of data by country of birth, particularly for the 16 seroconverter cases, did not allow this variable to be included in the analysis as no cases were observed in women coming from Latin American or Central Europe. Table 2 shows a statistically significant association between HIV seroconversion and age, the older the prostitutes the lower the risk (relative risk for 1 year older $(\mathrm{RR})=0.86,95 \%$ CI: 0.77-0.96). The workplace where women practised prostitution was also statistically associated to the risk of HIV seroconversion $(\mathrm{p}=0.03)$; women practising in flats or private referral presenting the lower risk and those practising at the streets the higher risks ( $R R=4.30,95 \% C I: 1.20-15.41)$. In relation to the duration of prostitution as measured in months and the number of clients per week reported at the first visit and the last visit (table 2), there was no evidence of any significant association with the risk of HIV infection.

A statistically significant association between IDU and HIV infection was observed, RR = 12.82 (95\% CI: 4.81-34.15). When the effect of having a regular partner who was an IDU was explored, a very strong positive association was observed with the risk of HIV infection, $\mathrm{RR}=20.89$ (95\%CI: 7.44-58.70). Those female sex workers who reported having a regular partner who was HIV positive $(n=13)$ also showed a higher risk of getting the HIV infection, the association being statistically significant, $\mathrm{RR}=6.04$ (95\%CI: 1.3-26.58). A reported past transfusion was not associated with a higher risk of HIV infection.

When all variables that reached statistical significance in the univariate analysis were entered in multivariate Poisson regression models using an upward stepwise procedure, only having a regular sexual partner who was an IDU and IDU remained as the independent predictors of the risk of HIV infection, although there was also some evidence that age was inversely associated with HIV infection. The large relative risks initially observed for IDU sex workers and for those women having a regular partner who was an IDU were substantially attenuated when their effects were controlled in a bivariate analysis based in 627 observations (table 3 ). Having a regular partner who was an IDU still persisted as the strongest predictor of the risk of infection when the effect of IDU was controlled, $\mathrm{RR}=10.08 \quad(95 \% \quad \mathrm{CI}: 2.94-34.57) . \quad$ The 
negative association observed for age in the simple analysis was attenuated and lost its statistical significance in multivariate analyses when the effect of a regular IDU partner and IDU were considered $(\mathrm{RR}=0.90,95 \% \mathrm{CI}$ : 0.79-1.02). Interaction terms for the main interest variables were explored in the multivariate analysis, but none was statistically significant.

\section{Discussion}

In this prospective study of female sex workers in Spain, a considerable incidence for HIV infection has been estimated, and a statistically significant association between the risk of HIV seroconversion and to have an IDU partner and being an IDU has been demonstrated. Although the possibility that infection through sex with clients cannot be precluded among these women, the results from this study are in accordance with other studies carried out in developed countries where the risk factors associated with HIV transmission were basically related to IDU. ${ }^{1}{ }^{6} 812-14$

The risk of HIV infection for non-IDU females sex workers in our setting may be considered low. Five of 16 female who seroconverted were not IDU, and did not have an IDU regular partner. One of these five women was born in an African country, and was the only seroconversion to HIV-2 which occurred after she was on a visit to her country; a second woman reported having had an IDU partner before entering the study as well as her IDU brother dying from AIDS; a third woman declared she had three regular partners during the study period; and another woman reported a past transfusion. However, as the pool of HIV positive prostitutes is increasing mainly because of the drug using behaviour of their usual partners, the risk of heterosexual transmission may also be increased. In addition, studies of IDU in the same geographic area have shown that the HIV-1 prevalence among male IDU was $50 \%$, and that $40 \%$ of these male IDU reported to have at least one contact with prostitutes, either having sex with prostitutes or with their girlfriends, in all cases with a low proportion using condoms in their sexual practices. ${ }^{15-17}$ Thus, regular partners of female sex workers probably play an essential role on the risk and the control of the infection, as this group of people may be very reluctant to use any intervention aimed at reducing the risk of HIV infection. With respect to this question, couple counselling in combination with social support has been suggested as an effective means of promoting and maintaining behaviour change among HIV infected people and their heterosexual partners. ${ }^{18}$ Therefore, the implementation of these strategies should be thoroughly pursued among those IDU female sex workers and those with IDU sexual partners in our area, in addition to regular HIV testing and counselling which has also been shown to be effective among drug using prostitutes. ${ }^{19}$

A general problem with estimates of relative risks in this study is the wide confidence intervals owing to the relatively small number of
HIV seroconverted women, particularly in some multivariate analyses. In spite of this problem, statistical significance was reached for the main interest variables because of the very strong effects. We should be wary of misclassification in studies with small numbers, but results from incidence studies similar to this are much better at identifying factors related to the risk of HIV seroconversion and reducing any source of potential misclassification bias, particularly those with a prior knowledge of a positive serological status.

With respect to the representativeness of participant prostitutes, non-participant prostitutes who only went once to the AIDS centre were slightly younger and reported a higher proportion of condom use with their clients. However, these small differences should not affect the internal validity of the study results, and since these variables were not associated with the risk of seroconversion, and no significant differences were observed between participants and non-participants in the IDU related variables, our results could be relevant to all prostitutes working in Alicante. Participation of these special groups of people has been quite successful for different reasons: women working in the AIDS centre were experienced and were very strict in maintaining confidentiality. Interventions to reduce the risk of HIV infection in female sex workers have usually focused on female sex workers as transmitters of the infection, and therefore promoted the use of condoms for commercial sex. Our findings would support the promotion of safer practices in non-commercial sex of prostitutes with their usual partners, particularly among those prostitutes linked to the use of injecting drugs.

These prostitutes and their partners should probably be the main target group for educational and other intervention efforts including those on drug use practices.

The authors thank Anneke van den Hoek, Maria Prins, and Alvaro Muñoz for their critical review and thoughtful comments on previous versions of this paper.

This project has been supported by grants of the Generalitat This project has been supported by grants of the Generalitat (FIS 89/0775, FIS 95/1688).

Individual contributions from authors not available.

1 Mckeganey NP. Prostitution and HIV: what do we know and where might research be targeted in the future? AIDS $1994 ; 8: 1215-26$

2 Kreiss JK, Koech D, Plummer FA, et al. AIDS virus infection in Nairobi prostitutes. Spread of the epidemic to East Africa. N Engl f Med 1986;314:414-8.

3 Plummer FA, Simonsen JN, Cameron DW, et al. Cofactors in male-female sexual transmission of human inmunodeficiency virus type 1 . F Infect Dis 1991;163:233-9.

4 Nzila N, Laga M, Abib Thiam M, et al. HIV and other sexually transmitted diseases among female prostitutes in Kinally transmitted diseases among
shasa. AIDS 1991;5:715-21.

5 Kunawararak P, Beyrer C, Natpratan C, et al. The epidemiology of HIV and syphilis among male commercial sex workers in nothern Thailand. AIDS 1995;9:517-21

6 European Working Group on HIV Infection in Female Prostitutes. HIV infection in European female sex workers: epidemiological link with use of petroleum-based lubricants. AIDS 1993;7:401-8.

7 Thomas RM, Plant MA, Plant ML, et al. Risks of AIDS among workers in the "sex industry": some initial results from a Scottish study. BMF 1989;299:148-9.

8 Van Den Hoek JAR, Coutinho RA, Van Haastrecht HJA, an Den Hoek JAR, Coutinho RA, Van Haastrecht HJA, et al. Prevalence and risk factors of HIV infections among drug users and drug-using prostitutes in Amsterdam. AIDS

9 Pineda JA, Aguado I, Rivero A, et al. HIV-1 infection among non-intravenous drug user female prostitutes in Spain. No evidence of evolution to Pattern II. AIDS 1992;6:1365-9. 
10 Breslow NE, Day NE, eds. Statistical methods in cancer research. Vol 2. The design and analysis of cohort studies. Lyons, France: International Agency for Research on Cancer, 1987 (Pub No 82).

11 EGRET. Seatle: Statistics and Epidemiology Research Corporation, 1991 .

12 Hernández I. Fernández E, García M, et al. Infección por el virus de la inmunodeficiencia humana tipo 1 en prostitutas y factores de riesgo. Med Clin (Barc) 1992;99:406-9.

13 Ward H, Day S, Mezzone J, et al. Prostitution and risk of HIV: female prostitution in London. BMF 1993;307:3568.

14 Aim G, De Vicenzi I, Ancelle-Park R, et al. HIV infection in French prostitutes. AIDS 1989;3:767-8.

15 Hernández-Aguado I, Bolumar F. Determinants of HIV-1 infection in intravenous drug users in Valencia, Spain, 1987-91. Int f Epidemiol 1993;22:537-40.
16 Hernández-Aguado I, Santos C, Torrella A, et al. Prevalencia de la infección por el virus de inmunodeficiencia humana en consumidores de drogas por vía parenteral en la Comunidad Valenciana (1987-1991). Med Clin (Barc) 1993;100:164-7.

17 Hernández-Aguado I, Ruiz I, Bolumar F, et al. Sharing of injection equipment among 3755 intravenous drug users in Valencia, Spain, 1987-1992. Int f Epidemiol 1994;23:6027.

18 Padian NS, O'Brien TR, Chang YC, et al. Prevention of heterosexual transmission of human inmunodeficiency virus through couple counseling. F Acq Immun Def Synd 1993;6:1043-8.

19 van Ameijden EJ, van der Hoek AJ, van Haastrech HJ, et al. Trends in sexual behaviour and the incidence of sexually transmitted diseases and HIV among drug-using prostitutes, Amsterdam 1986-1992. AIDS 1994;8:213-21. 